\title{
Breve esboço acerca do transhumanismo
}

\section{A brief draft about transhumanism}

\author{
TIAGO XAVIER ${ }^{1}$
}

Resumo: Este trabalho tem por objetivo apresentar, de forma breve, o transhumanismo e o seu ideal de evolução humana, uma vez que esse movimento cultural entende que o homem deve evoluir a níveis demasiadamente elevados para além da sua menoridade estrutural rompendo com cadeias biológicas através da alteração de sua natureza.

Palavras-chave: Transhumanismo. Aprimoramento-humano. Pós-humanismo.

\begin{abstract}
This work itens to present, in a brief way, transhumanism and its ideal of human evolution, since this cultural movement asserts that man must evolve to the higher levels, evolving far beyond its lesser condition - breaking up biological chains through change of its nature.
\end{abstract}

Keywords: Transhumanism. Human enhacement. Post humanism.

Em seu trabalho intitulado Transhumanism: toward a futurist philosophy, Max More esclarece que o transhumanismo ${ }^{2}$ é uma classe de filosofias que buscam conduzir a humanidade a um estágio pós-humano, valorizando a razão e a ciência, compromissada com o progresso e existência terrena, e não com uma vida metafísica, sobrenatural (como a do humanismo cristão) ${ }^{3}$. Por isso, se difere dela, reconhecendo e antecipando alterações na natureza humana e as possibilidades de progresso $^{4}$.

\footnotetext{
${ }^{1}$ Graduação e mestrado em Filosofia pela Universidade Federal do Rio Grande do Norte (UFRN). Doutorando em filosofia pela mesma instituição. E-mail: sophosxavier@hotmail.com

${ }^{2}$ Termo criado pelo biólogo britânico Julian Sorell Huxley (1887-1975) em 1957; mas é ao filósofo e futurista britânico Max More que são atribuídos os créditos à filosofia atual desse movimento. É importante ressaltar que há várias correntes transhumanista, a saber, "Transhumanismo libertário", "Pós-generismo", "Singularitarianismo", "Tecno-gaianismo" etc. Contudo, não pretendendo aqui apresentá-las, e muito menos distinguir suas formas, mas apenas abordar alguns aspectos do trajeto trilhado por este movimento cultural que segue uma meta: "pós-humanismo" (fase evoluída que ultrapassa a do homem natural, puramente biológico), como bem notou Luc Ferry em A revolução transumanista ao dizer que "seria preciso reservar o termo 'pós-humanismo' para" este movimento cultural, "já que se trata de criar uma espécie nova, radicalmente diferente da nossa, milhares de vezes mais inteligente e mais poderosa, outra humanidade. Assim, vemos que esse é verdadeiramente um pós-humanismo, já que defende não a simples melhoria da humanidade atual, mas a fabricação de outra espécie, uma espécie que, no limite, não terá mais muito a ver com a nossa”. O transhumanismo "é o trajeto, enquanto o pós-humanismo é a meta; um é o caminho ou processo, o outro é o resultado ou o ponto de chegada" (2018, p. 8-10).

${ }^{3}$ Os adeptos dos ideais transhumanistas "são partidários da razão, do progresso [...] renegando valores centrados em autoridades religiosas ou dogmas", como bem destacou Edgar Silveira Franco em $O$ Manifesto da Arte Extropiana e a obra PRIMO 3M+: Proposta para um Corpo Pós-Humano. Disponível em: <http://www.compos.org.br/data/biblioteca_953.pdf>. Acesso em: 10 de dez. 2018.

4 MORE, M. Transhumanism: toward a futurist philosophy. Disponível em: < https://pt.scribd.com/doc/257580713/Transhumanism-Toward-a-Futurist-Philosophy>. Acesso em: 15 de ago. 2018.
} 
Já Nick Bostrom, um dos principais adeptos deste movimento, vê o transhumanismo como um modo de se indagar sobre o futuro, apoiado na ideia de que a espécie humana atual não representa o fim do desenvolvimento humano, vendo-a como algo que está sendo construído, pois o homem não é o estágio final da evolução humana 5 .

Os adeptos desse movimento anseiam transcender a condição humana a partir da simbiose homem e máquina que aumentará consideravelmente as capacidades físicas, intelectuais e psicológicas do ser humano com a ajuda da ciência e tecnologia, promovendo um ser híbrido - capaz de ir além dos limites da biologia humana. E uma vez que estamos inseridos em um intenso processo de hibridização cultural que promove a construção de identidades abertas ${ }^{6}$, o transhumanismo cresce vertiginosamente, alimentando um sonho antigo do homem: a autossuperação humana.

Para isso a filosofia do transhumanismo, amparada pelos crescentes avanços de novas tecnologias, está disposta a contribuir para que o sonho da autossuperação humana se torne menos utópico, uma vez que o desenvolvimento de tecnologias amplamente disponíveis está investindo maciçamente na ideia de aumentar as capacidades do ser humano. A pretensão é habilitar cada vez mais o homem com atributos especiais, dotando-o de capacidades que ele não tem por natureza, a fim de que evolua para além das limitações físicas e mentais?

Por conta disso o transhumanismo carrega consigo a ideia "de que um progresso sem fim, uma perfectibilidade ilimitada da espécie humana, é ao mesmo tempo possível e desejável" (FERRY, 2018, p. 2). Neste sentido, "uma das características mais essenciais do movimento" é o de "passar do paradigma médico tradicional, o da terapêutica, cuja finalidade principal é 'reparar', curar doenças e patologias, para um modelo 'superior', o da melhoria, ou até do 'aumento' do ser humano" (FERRY, 2018, p. 1).

Essas pretensões são ordenadamente apresentadas em um texto que reúne a ideologia deste movimento cultural, intitulado Principles of Extropy ${ }^{8}$ - princípios da extropia $^{9}-$, escrito por Max More, que traz as seguintes ideias:

\footnotetext{
5 BOSTROM, Nick. Transhumanist values. Philosophical Documentation Center Press, 2003 Disponível em: <https://nickbostrom.com/ethics/values.html>. Acesso em: 05 de jan. 2019.

${ }^{6}$ Conjunto de caracteres particulares com que o indivíduo identifica-se, escolhe e toma para si a partir das suas experiências, se reconhecendo da forma que lhe apraz.

${ }^{7}$ MOTTA, Heuring Felix. Transhumanismo: o nascimento de uma nova humanidade! Disponível em: $<$ https://www.conscienciacristanews.com.br/transhumanismo/>. Acesso em: 04 de set. 2018.

8 MORE, M. Principles of Extropy. Version 3.11 (c) 2003. Disponível em: < https://web.archive.org/web/20131015142449/http://extropy.org/principles.htm>. Acesso em: $11 \mathrm{de}$ dez. 2018.

9 Termo que traz uma ideia oposta a da "Entropia". O termo "Extropia" representa "uma espécie de síntese do movimento científico e filosófico que nomeia, ele é usado como uma medida de informação, inteligência, vitalidade, diversidade, oportunidade e desenvolvimento, opondo-se de forma
} 
- Progresso perpétuo: buscar mais inteligência e sabedoria de forma eficaz em prol de uma expectativa de vida saudável e ilimitada;

- Autotransformação: afirmar continuamente o aperfeiçoamento físico, intelectual e ético por meio do pensamento crítico e do uso amplo da tecnologia em prol do aumento fisiológico e neurológico, contribuindo para o refinamento emocional e psicológico;

- Otimismo prático: alimentar as ações, os indivíduos e as organizações com expectativas positivas, adotando um otimismo racional e proativo em lugar do pessimismo e da fé cega;

- Tecnologia inteligente: aplicar a ciência de forma criativa, projetando e gerenciando tecnologias como meios efetivos para melhorar a vida transcendendo as qualidades "naturais" derivadas da herança biológica;

- Sociedade aberta - informação e democracia: apoiar ordens sociais que promovam a liberdade de comunicação, ação, experimentação, inovação etc., opondo-se ao controle social autoritário e à hierarquia desnecessária, favorecendo o Estado de Direito e a descentralização do poder e da responsabilidade;

- Auto-direção: valorizar o pensamento independente, a responsabilidade pessoal, a liberdade individual e o respeito próprio;

- Pensamento racional: entender, experimentar, aprender, desafiar e inovar favorecendo a razão sobre a fé cega.

Essas ideias demonstram um

[...] novo dogma que postula, assim como tantas religiões ocidentais, a possibilidade de alcançarmos uma "vida eterna", não no sentido transcendentalista, mas sim diante das possibilidades vislumbradas pelos atuais avanços científicos que poderão permitirnos continuar vivos ad infinitum ${ }^{10}$.

contundente a um conceito tradicional da física, a 'Entropia', segundo o qual todos os sistemas sofrem uma perda constante de energia tendendo à falência/extinção; dessa forma, a Extropia desafia esse princípio propondo uma expansão sem limites, da vida e da consciência", como bem destacou Edgar Silveira Franco em O Manifesto da Arte Extropiana e a obra PRIMO $3 M_{+}$: Proposta para um Corpo PósHumano. Disponível em: <http://www.compos.org.br/data/biblioteca_953.pdf>. Acesso em: 10 de dez. 2018.

${ }^{10}$ FRANCO, Edgar Silveira. O Manifesto da Arte Extropiana e a obra PRIMO $3 M_{+}$: Proposta para um Corpo Pós-Humano. Disponível em: <http://www.compos.org.br/data/biblioteca_953.pdf>. Acesso em: 10 de dez. 2018. 
Tudo isso pode parecer ficção científica, sonho tecnocientífico de uma

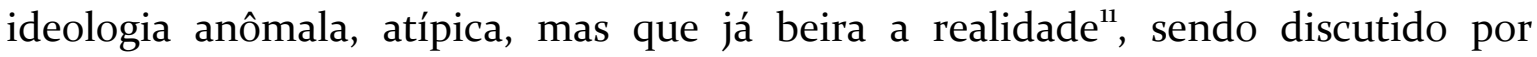
intelectuais de várias áreas do saber, protagonizando o debate acerca do que o filósofo Julian Savulescu chamou de pós-humano: forma de vida evoluída que se distinguirá significativamente de qualquer aspecto natural (biológico) do homem por se encontrar em um estágio para além deste ${ }^{12}$. Tal estágio será

[...] alcançado através da aplicação de técnicas de manipulação, instrumentalização e artificialização da vida, do patrimônio biológico humano, acarretando uma mudança de estatuto especista. Quer dizer, o humano, por iniciativa própria e com vistas ao melhoramento da sua natureza, deixará de ser humano (VILAÇA \& DIAS, 2014, p. 342.

A mudança da condição biológica do homem por meio do processo de alteração dará origem a uma forma de vida pós-humana. Limitações, enfermidades e toda forma de sofrimento que acomete o homem poderão ser superadas, já que a crença é de que as

[...] capacidades mentais, corporais, morais e emocionais poderão ser melhoradas, sendo ampliadas a um nível de eficiência ainda inimaginável. Em tese, melhoraria a qualidade de vida, elevando o nível de bem-estar individual e, quiçá! coletivo (VILAÇA \& DIAS, 2014, p. 344).

As ideias de aprimoramento, ampliação e ultrapassagem dos limites humanos (superando até mesmo a morte) estão enraizadas na filosofia dos transhumanistas por estarem convictos de que o ser humano pode e deve se desenvolver a níveis demasiadamente elevados, evoluindo para além da sua menoridade estrutural rompendo com cadeias biológicas através da alteração de sua natureza, o que possibilitará o surgimento do super-humano, o qual será imortal .

Para os adeptos desse movimento, a natureza humana é a biológica, considerada básica, precária e vulnerável, instigando-os a acreditarem que "as características (biológicas) do humano devem ser alteradas, tornando-o mais 'feliz', 'saudável' e 'longevo'” (VILAÇA \& DIAS, 2014, p. 347), ainda que esta alteração torne-o artificial, já que para eles

[...] não há nenhuma virtude especial (maior valor) em fazer parte da espécie humana, pois "pertencer à espécie humana" é uma mera

\footnotetext{
${ }^{11}$ Os ideais transhumanistas já estão sendo trabalhados, recebendo o apoio de várias universidades, centros de pesquisa, empresas e laboratórios espalhados pelo mundo. A título de exemplo, o movimento "recebe o apoio de várias associações internacionais, entre as quais o Extropy Institute, a World Transhumanist Association, [...] Aleph, na Suécia, Transcendo, na Holanda etc". Recebe também financiamento de "empresas envolvidas no desenvolvimento de novas tecnologias, como Google", por exemplo; esta financiadora da "Universidade da Singularidade" (FERRY, 2018, p. 1 e 8).

${ }^{12}$ SAVULESCU, J.; BOSTROM, N. Human enhancement. Oxford: Oxford University Press, 2009.
} 
contingência, podendo acarretar até mesmo certos prejuízos. De acordo com alguns transhumanistas, a moralidade humana não está fundamentada numa noção abstrata de natureza humana, mas sim na sua dimensão biológica, podendo, inclusive, ser "prejudicada" por esta. Desse ponto de vista, a natureza humana pode e deve ser alterada, pois, ao invés disso gerar prejuízos à humanidade, trará benefícios substantivos (VILAÇA \& DIAS, 2014, p. 351-352).

O homem natural não é o fator principal para os adeptos do movimento transhumanista, por ser antigo, velho e cheio de características que o limitam, devendo ser transcendido por meio da ampliação do ciclo da vida que abrirá caminho para o nascimento de uma nova era voltada inteiramente para a mudança e evolução, na qual a tecnologia estará totalmente compromissada em realizar a renovação do humano, reconstruindo-o a partir da fusão da biologia com a máquina, rompendo com as fronteiras humanas marcadas pela enfermidade, dor, sofrimento, morte e luto - ingressando numa existência na qual todas as características naturais do corpo estarão potencializadas.

\section{Considerações finais}

Os ideais de evolução promovidos pelo transhumanismo contagiam o homem do novo milênio de tal forma que o fazem crer que a ideia de ampliar as suas capacidades é necessária para si, fazendo-nos lembrar da observação feita por Pitágoras de que, dentre os animais, o homem é o mais calamitoso, pois todos os outros se contentam com os limites prefixados da sua natureza, enquanto só ele insiste em ultrapassar os limites da sua. Mas, uma vez que "só o homem goza do privilégio de aprender as artes e as ciências, a fim de suprir com os seus conhecimentos às lacunas da natureza" (ROTTERDAM, 2002, p. 24), é mais do que comum a não aceitação dos limites impostos a ele, identificando-se com tudo aquilo que promova a superação desses limites.

E é por essas e outras que o transhumanismo promove a ideia de imersão em uma nova era na qual todas as características do corpo estarão aprimoradas, entendendo que o homem não é o estágio final da evolução humana, devendo ser superado a partir de aparatos tecnológicos que proporcionarão o aumento das suas capacidades.

\section{Referências}

AGAR, N. Liberal eugenics: in defence of human enhancement. Hoboken: Blackwell Publishing, 2004.

BOSTROM, N. A history transhumanist thought. Journal of evolution and technology, v. 14, n. 1, p. 1-25, 2005.

In defense of posthuman dignity. Bioethics. Vol. 19, No. 3-2005a. Disponível em: <https://nickbostrom.com/ethics/dignity.html> Acesso em: 26 de jun. 2018. 
. Transhumanist values. Philosophical Documentation Center Press, 2003. Disponível em: <https://nickbostrom.com/ethics/values.html>. Acesso em: o5 de jan. 2019.

BUCHANAN, A. Human nature and enhancement. Bioethics, v. 23, n. 3, 2009, p. 141-150.

COECKELBERGH, M. Human being @ risk enhancement, technology, and the evaluation of vulnerability transformations. Nova Iorque: Springer, 2013.

DA SILVA, M. R. As controvérsias a respeito da participação de Rosalind Franklin na construção do modelo da dupla hélice. Scientiæzudia, São Paulo, v. 8, n. 1, p. 69-92, 2010.

DUPUY, J-P. O transumanismo e a absolescência do homem. In: NOVAES, A. (Org.). A condição humana: as aventuras do homem em tempos de mutações. São Paulo: Agir, 2009.

FARRELL, J. P.; HART, S. D. de. Transhumanism: a grimoire of alchemical altars and the agenda for the apocalyptic transformation of man. Washington: Feral House, 2011.

FELDHAUS, C. O futuro da natureza humana de Jürgen Habermas: um comentário. Revista Ethic@. Vol. 4, no. 4, p. 309-319, ano 2005.

FERKISS, V. Technology and culture: Gnosticism, naturalism and incarnational integration. CrossCurrents Vol. 30, №. 1, p. 13-26,1980.

FERRAZ, M. C. Franco. Sociedade Tecnológica: de Prometeu a Fausto. Revista Contracampo: Programa de pós graduaçao em comunicaçao. UFF. n. 04, 2000.

FERRY, L. A revolução transumanista. Tradução de Éric R. R. Heneault. Barueri, SP: Manoel, 2018.

FM-2030. Are you a transhuman? Monitoring and stimulating your personal rate of growth in a rapidly changing world. New York, NY: Warner Books, 1989.

FRANCO, E. S. O Manifesto da Arte Extropiana e a obra PRIMO 3M+: Proposta para um Corpo Pós-Humano. Disponível em: <http://www.compos.org.br/data/biblioteca_953.pdf>. Acesso em: 10 de dez. 2018.

FUKUYAMA, F. Nosso futuro pós-humano: consequências da revolução da biotecnologia. Rio de Janeiro: Rocco, 2003.

GARCIA, J. L. A plenitude tecnológica em questão. Hermínio Martins e o Experimentum humanum: civilização tecnológica e condição humana. Análise Social, Lisboa, v.47, n.2, p. 483-489. 2012.

GIZMODO. Tudo o que você precisa saber sobre a CRISPR, nova ferramenta de edição de DNA. Disponível em: <http://gizmodo.uol.com.br/tudo-o-que-voce-precisa-saber-sobre-acrispr-nova-ferramenta-de-edicao-de-dna/>. Acesso em: 11 de mar. 2018.

HABERMAS, J. O futuro da natureza humana: a caminho de uma eugenia liberal?. São Paulo: Martins Fontes, 2004.

HARRIS, J. Enhancing evolution. New Jersey: Princeton University Press, 2007.

HEIDEGGER, M. A questão da técnica. Tradução de Marco Aurélio Werle. Scientiæ Zudia: São Paulo, v. 5, n. 3, p. 375-98, 2007.

Serenidade. Instituto Piaget: Rio de Janeiro, 2001.

HUXLEY, Aldous. Admirável mundo novo. São Paulo: Abril Cultural, 1974 - $1^{\mathrm{a}}$ ed.

JONAS, H. "The burden and blessing of immortality”. Hasting Center Report, 22(1), 1992, p. 34-41.

KASS, R. L. Life, liberty and defense of dignity: the challenge for bioethics. San Francisco: 
Encounter Books, 2002.

KHALSA, D. S; STAUTH, Cameron.; BELLO, Sylvia. Longevidade do cérebro: um programa médico revolucionário que aprimora a mente e a memória. 13. ed. rev. Rio de Janeiro, RJ: Objetiva, c1997. $451 \mathrm{p}$.

KINOUCHI, R. R. O homem como experimento tecnológico de si. Revista História, Ciência, Saúde - Manguinhos, Rio de Janeiro. v. 21, n. 1, 2014, p. 357-36o.

KIRKWOOD, T. Os melhores anos de nossas vidas. Tradução de Ruy Jungmann. Rio de Janeiro: Record, 2001a.

The end of age. London: Profile Books, 2001.

KURZWEIL, R. The age spiritual machines. Viking Press, 1999.

The singurality is near: when humans transcend biology. Penguin Group, 2005.

LENT, R. Cem bilhões de neurônios: conceitos fundamentais de neurociência. Rio de Janeiro: Atheneu, 2010.

LEOPOLDO E SILVA, F. “A invenção do pós-humano”. In: NOVAES, A. (org.). A condição humana: as aventuras do homem em tempos de mutação. São Paulo, Ed. SESCSR e Ed. Agir, 2009.

MORE, M. Principles of Extropy. Version 3.11 (c) 2003. Disponível em: < https://web.archive.org/web/20131015142449/http://extropy.org/principles.htm>. Acesso em: 11 de dez. 2018.

Transhumanism: toward a futurist philosophy. Disponível em: < https://pt.scribd.com/doc/257580713/Transhumanism-Toward-a-Futurist-Philosophy>. Acesso em: 15 de ago. 2018.

MOREIRA et al. Biosensores: tecnologia e aplicações. Disponível em: $<$ http://www.biologia.seed.pr.gov.br/arquivos/File/biotecnologia/biosensores.pdf $>$. Acesso em: 30 de dez. 2018.

MOTTA, H. F. Transhumanismo: o nascimento de uma nova humanidade! Disponível em: $<$ https://www.conscienciacristanews.com.br/transhumanismo/>. Acesso em: 04 de set. 2018.

NAHRA, C. M. L. O dia em que a morte morrerá. Rev. Veritas - RS. v. 58, n. 1, (2013).

NAISBITT, J. High Tech High Touch - A tecnologia e a nossa busca por significado. São Paulo: Cultrix, 2000.

NÁPOLI, C. de. A fórmula da eterna juventude e outros experimentos nazistas. Disponível em: <https://rosid.myboek.xyz/download/a-formula-da-eterna-juventude-e-outrosexperimentos-nazistas-br598939207.html> Acesso em: 15 de out. 2018.

NUNES, B. No tempo do niilismo e outros ensaios. São Paulo: Ática, 1993.

PESSINI, L. Bioética e o desafio do transhumanismo. Ideologia ou utopia? Ameaça ou esperança?. In: Sujeito na educação e saúde. São Paulo: São Camilo e Loyola, 2007.

PORFIRIO. Vida de Pitágoras (Argonáuticas órficas - Himnos órficos). Madrid: Gredos, 1987.

ROTTERDAM, E. de. Elogio da Loucura. eBooksBrasil, 2002. Disponível em: $<$ https://www.cairu.br/biblioteca/arquivos/Filosofia/Elogio_Loucura_Hume.pdf $>$. Acesso em: 03 de out. 2018.

RÜDIGER, F. Cibercultura e pós-humanismo. São Paulo: Unicamp, 1988. 
SANDEL, M. J. Contra a perfeição: ética na era da engenharia genética. 1. ed. Rio de Janeiro, RJ: Civilização Brasileira, 2013.

SAVULESCU, J.; BOSTROM, N. Human enhancement. Oxford: Oxford University Press, 2009 .

SLOTERDIJK, P. Regras para o parque humano: uma resposta à carta de Heidegger ao humanismo. São Paulo: Estação Liberdade, 2000.

SORGNER, S. L. Menschenwürde nach Nietzsche: die Geschichte eines Begriffs. Volume IV, Issue II, p. 1-10, Fall 2011. Disponível em:<http://www.nietzschecircle.com/AGONIST/2011_o8/CONTENTS.html>. Acesso em: 05 de set. 2018.

. Nietzsche, the overhuman and transhumanism. Journal of Evolution and Technology

- Vol. 20 Issue 1 - mar. 2009. p. 29-42, 2009. Disponível em:

<https://jetpress.org/v2o/sorgner.htm>. Acesso em: Acesso em: 11 de jul. 2018.

SORGNER, S. L; ERLANGEN. Further Remarks on the Complex Relationship between Nietzsche and Transhumanism. Volume IV, Issue II, p. 1-46, Fall 2011.

Disponívelem:<http://www.nietzschecircle.com/AGONIST/2011_08/CONTENTS.html>. Acesso em: 10 de set. 2018.

TOURAINE, A. Crítica da modernidade. 3. ed. Petrópolis: Vozes, 1995.

VILAÇA, M. M. Qual natureza humana? Que aperfeiçoamento? Qual futuro? Reflexões em torno do conceito de natureza humana ampliada. Ethic@. Florianópolis, v. 12, n. 1, p. 25-51, 2013.

VILAÇA, M. M.; DIAS, M. C. M. Transumanismo e o futuro (pós-) humano. Rev. Physis revista de saúde coletiva - Rio de Janeiro, 24 [2]:341-362, 2014.

VVAA. A década do cérebro e da neurotecnologia. In: Revista Marketing. Disponível em: <http://propmark.com.br/revista-marketing/a-decada-do-cerebro-e-da-neurotecnologia>. Acesso em: o5 de jul. 2018.

WILLIAM, E. Pluralistic Sense-Making: A World of Becoming. Volume IV, Issue II, Fall 2011. p. 1-12. Disponível em:<

http://www.nietzschecircle.com/AGONIST/2011_o8/CONTENTS.html>. Acesso em: o7 de set. 2018.

Submissão: 05. 03. 2019 / Aceite: 25. 08. 2019 